\title{
UWB Radar: Vision through a wall
}

\author{
Ondrej Sisma $^{1}$, Alain Gaugue ${ }^{1}$, Christophe Liebe $^{1}$, Jean-Marc Ogier ${ }^{1}$ \\ ${ }^{1}$ Laboratoire Informatique, Image et Interaction (L3i), Université de La Rochelle \\ Pôle Science et Technologie, 17042 La Rochelle Cedex 1 \\ sismaol@fel.cvut.cz,christophe.liebe@univ-lr.fr
}

\begin{abstract}
There exist a lot of methods for vision through an opaque medium. At present UWB (Ultra-Wideband) technology is used more and more because it is suitable for localization and detection of a human body behind a wall. First of all this paper describes known methods for vision through walls, which can be divided into two general groups - imaging and non-imaging systems. Secondly it describes the state of the art UWB radar for this application and its specifics. Finally it depicts our UWB radar system (centre frequency $4,7 \mathrm{GHz}$ ) and our practical procedures relevant to the detection of a human body presented behind a concrete wall.
\end{abstract}

Keywords: UWB, radar, through-the-wall surveillance, imaging system, nonimaging system, bistatic radar.

\section{Introduction}

Detection of persons and things behind an opaque medium is a very interesting theme for a wide range of industries and in following years this issue will constitute a strategic point of applicability in biomedical engineering, security service, agricultural industry, etc. For example, a through-the-wall surveillance (TWS) could be utilized in searching for people in rubble and in buildings on fire. The military could use this technology for bomb-disposal, neutralization of aggressors, hostage rescue, etc.

Different technologies are applicable for through-the-wall surveillance: radio frequency (RF) technologies (from the UHF radar to the submillimeter wave imager), acoustic, X-ray scanner. These all appear to offer a partial solution. The desire to see through a wall creates a technical conflict between the possibility of successfully penetrating the wall, which implies lower frequencies, and the possibility of obtaining maximum resolution for the image, which implies higher frequencies. Perhaps one exception to this is the X-ray system which provides both good resolution and good penetration, but is limited to very short ranges and has safety risks.

The text below elaborates on vision through walls system based on radio frequency. These can be classed in two categories: low frequency non-imaging systems that have good wall penetration capabilities but low spatial resolution, and high frequency imaging systems with limited wall penetration capabilities. 


\section{Imaging systems}

The through-the-wall imaging systems (TWIS) allow an image to be obtained from behind a wall (only the shape of the person or object, not an optical image). Two categories of system exist: active millimetre wave cameras (AMMW), a system functioning like a microwave radar and passive millimetre wave cameras (PMMW), a system similar to a radiometer. The principal characteristics of these systems described below are given in Table 1 .

\subsection{AMMW camera}

In the middle of 1990 , Millimetrix with the consortium MIRTAC developed a $94 \mathrm{GHz}$ imaging radar for TWS. The latest version was developed by Millivision. This system consists of a frequency modulated continuous wave (FMCW) transmitter (allowing 256 range bins over a $25 \mathrm{~m}$ range to be achieved) with a broad-beam antenna and a 256 element receiver array, 16 azimuth elements by 16 elevation elements (plus acquisition system, display, etc.). The cover area represents $11^{\circ}$ by $11^{\circ}$ by $25 \mathrm{~m}$ of coverage. To cover larger areas, antennas can scan to obtain a coverage at $33^{\circ}$ by $33^{\circ}$ by $25 \mathrm{~m}$, but this process requires up to 3 minutes to collect a single image. The output of the radar can be displayed in either 2-D or 3-D formats. Software was developed for interpreting the images.

In 1997, Hugues Adavanced Electromagnetic Technologies developed a millimetre wave radar that provides $2-\mathrm{D}$ or $3-\mathrm{D}$ images of scenes through interior walls. The radar operates at $50 \mathrm{GHz}$ with a $33 \mathrm{~cm}$ aperture and is mechanically scanned over an angular sector of up to $+/=30^{\circ}$ to obtain an image.

In 2004, the Swedish Defence Research Agency (FOI) developed a millimetre wave imaging radar. This radar system is a $94 \mathrm{GHz}$ imaging pulse radar system comprising a 32 element receiver array, 4 azimuth elements by 8 elevation elements. The resulting field of view is approximately $3^{\circ}$ by $5^{\circ}$. Typical indoor wall materials (plasterboard and chipboard) were tested: the distance to the person was $20 \mathrm{~m}$, and a wall was placed $5 \mathrm{~m}$ from the radar between the radar and the person.

\subsection{PMMW camera}

In 1996, Thermotrex developed an original concept of passive millimeter wave camera for security applications. The camera combines a phase array radio receiver with an acousto-optic processor to create a real time millimetre-wave to visible-light converter. Then the visible-light is detected using a standard video camera. The millimeter camera captures the incoming millimetre radiation through a 32 channel, $0.9 \mathrm{~m}^{2}$ array anterna. The antenna signal is downconverted from $94 \mathrm{GHz}$ to $9 \mathrm{GHz}$ for modulating the acousto-optic converter. For TWS applications, they tested their camera indoors. However to see something through a wall, the scene needs to be "backlit" by a metal mirror used to reflect external light. Since then, this architecture has been abandoned, because it was too expensive. 
Table 1. State-of-the-art imaging system of TWS (through-the-wall surveillance technology) Notice: ? = Unknown data

\begin{tabular}{|l|c|c|c|c|c|l|}
\hline $\begin{array}{l}\text { Authors } \\
\text { Company } \\
\text { System }\end{array}$ & $\begin{array}{l}\text { Freq. } \\
\text { (GHz) }\end{array}$ & $\begin{array}{l}\text { Input } \\
\text { type/ } \\
\text { size }\end{array}$ & $\begin{array}{l}\text { Spatial } \\
\text { Resolu- } \\
\text { tion }\end{array}$ & $\begin{array}{l}\text { Field } \\
\text { of } \\
\text { View }\end{array}$ & $\begin{array}{l}\text { Output } \\
\text { Dim/ } \\
\text { Type }\end{array}$ & Type (power) \\
\hline $\begin{array}{l}\text { N. Currie } \\
\text { Hugues AETC } \\
\text { [1] }\end{array}$ & 50 & $\begin{array}{c}\text { Lens } \\
300 \mathrm{~mm}\end{array}$ & $6 \mathrm{~cm}$ & $+/-30^{\circ}$ & $\begin{array}{c}3 \mathrm{D} \\
\text { Screen } \\
\text { monitor }\end{array}$ & $\begin{array}{l}\text { AMWI } \\
\text { Mechanic. } \\
\text { scanned. }\end{array}$ \\
\hline $\begin{array}{l}\text { Huguenin } \\
\text { Millivision } \\
\text { [2] }\end{array}$ & 94 & $\begin{array}{l}\text { Lens } \\
300 \mathrm{~mm}\end{array}$ & $12 \mathrm{~cm}$ & $33^{\circ} \times 33^{\circ}$ & $\begin{array}{l}\text { FMCW } \\
\text { Screen } \\
\text { monitor } \\
\text { AMWI } \\
\text { FPA 16x16 } \\
\text { Mechanic. } \\
\text { scanned. }\end{array}$ \\
\hline $\begin{array}{l}\text { J. Svedin SDRA } \\
\text { FOI) [3] }\end{array}$ & 94 & $\begin{array}{c}\text { Lens } \\
300 \mathrm{~mm}\end{array}$ & $4 \mathrm{~cm}$ & $3^{\circ} \times 5^{\circ}$ & $\begin{array}{c}2 \mathrm{D} \\
\text { Screen } \\
\text { monitor }\end{array}$ & $\begin{array}{l}\text { Impulse } \\
\text { AMWI } \\
\text { FPA 4x8 }\end{array}$ \\
\hline $\begin{array}{l}\text { Lovberg } \\
\text { Thermotrex [4] }\end{array}$ & 94 & $\begin{array}{c}\text { Array } \\
0.9 \times 0.9 \mathrm{~m}^{2}\end{array}$ & $4 \mathrm{~cm}$ & $6^{\circ} \times 8^{\circ}$ & $\begin{array}{c}\text { Screen } \\
\text { monitor }\end{array}$ & $\begin{array}{l}\text { PMMW } \\
32 \text { channel }\end{array}$ \\
\hline $\begin{array}{l}\text { Huguenin } \\
\text { Millitech } \\
\text { MAPS [5] }\end{array}$ & 95 & $\begin{array}{c}\text { Lens } \\
300 \mathrm{~mm}\end{array}$ & $7 \mathrm{~cm}$ & $?$ & $\begin{array}{c}2 \mathrm{D} \\
\text { Screen } \\
\text { monitor }\end{array}$ & PMMW \\
\hline
\end{tabular}

Millitech Corporation has also developed a PMMW imaging system for security applications. A demonstration of the system's ability to perform through-the-wall imaging was performed with an interior partition mounted on an external platform. A person behind this partition was well seen, and the good image quality showed that he was carrying a gun. Such a system can operate, but only with a high radiometric temperature difference between the person and the wall.

\section{Non-imaging systems}

These systems allow users to detect the presence of an individual through an intervening door or wall (any non-metallic wall) using a radio frequency sensing technique. Usually these systems use RF radar technologies at low frequencies, from UHF to microwaves.

\subsection{FMCW radar}

In 1992, Raytheon developed a monitoring system through-the-wall, called the Motion Detection Radar (MDR). This system consists of a UHF radar using a sensitive continuous wave $(\mathrm{CW})$ phase detector (centred at the frequency of $915 \mathrm{MHz}$ ). This radar detects motion and creates an audio tone which varies in pitch proportional to the motion that is being detected. These tones fluctuate (from $60 \mathrm{~Hz}$ to $300 \mathrm{~Hz}$ ) giving a relative indication of the distance from the radar and the speed at which the person is moving. The detected motion is between $0.1 \mathrm{~m} / \mathrm{s}$ and $1.7 \mathrm{~m} / \mathrm{s}$. For 
the MDR, the range in the open is approximately $30 \mathrm{~m}$. Through $15 \mathrm{~cm}$ of steel reinforced concrete this drops down to $10 \mathrm{~m}$. Through $1 \mathrm{~m}$ of concrete block wall it drops to about $6 \mathrm{~m}$.

In 1996, a new capability was added: measuring the distance to moving targets. The system provides not only an indication of movement of the target and its distance, but can also indicate that several individuals are moving. This new 2D-TWS radar system, known as the "2D Concrete Penetration Radar (2D-CPR)" was also developed by Raytheon. This radar is a frequency modulated continuous wave system (FMCW) with a $950 \mathrm{MHz}$ centre frequency and a sweep frequency band of 700 to $1200 \mathrm{MHz}$. For the 2D-CPR, the range in the open is approximately $30 \mathrm{~m}$. Through a $20 \mathrm{~cm}$ thick concrete-steel reinforcing, a target can be detected at more than $25 \mathrm{~m}$ from the inside wall, with a radar set up at a distance of $6 \mathrm{~m}$ from an outside wall. The principal characteristics of these two radars are given in Table 2. Finally, in 1999 a lightweight field portable version, called the Motion And Ranging Sensor (MARS), was developed by Raytheon. The key limitation of these radars is that if the target is not moving, an object can not be differentiated from a person.

In 1997, the Georgia Tech Research Institute developed a microwave radar, called the RADAR Flashlight. This system was designed to detect the respiration of a motionless human behind a wall. The laboratory unit is a homodyne FMCW radar which operates on a frequency near $10.525 \mathrm{GHz}$ (different frequencies had been tested up to $35 \mathrm{GHz}$ ). The radar output signal displays rises and falls of the rhythmic respiration response. The RADAR Flashlight can detect the respiration of a human standing up to $5 \mathrm{~m}$ away behind a $20 \mathrm{~cm}$ hollow-core concrete block wall.

At the same time, SRI International developed a laboratory UHF TWS system built with a network analyser, that is operated as a FMCW radar. The FMCW signal is transmitted from a centre antenna and received by two separate spatial receiver antennas. This particular set-up allows an ultra-wideband differential radar to be

Table 2. State-of-the-art non imaging systems - FMCW.

$*$ : Frequency is either the centre frequency or the frequency band

\begin{tabular}{|c|c|c|c|c|c|c|}
\hline $\begin{array}{l}\text { Authors } \\
\text { Company } \\
\text { System }\end{array}$ & $\begin{array}{l}\text { Freq.* } \\
\text { (GHz) }\end{array}$ & $\begin{array}{l}\text { Input type / } \\
\text { size }\end{array}$ & $\begin{array}{l}\text { Spatial } \\
\text { Resolu- } \\
\text { tion }\end{array}$ & $\begin{array}{l}\text { Ficld } \\
\text { of } \\
\text { View }\end{array}$ & $\begin{array}{l}\text { Output } \\
\text { Dim / } \\
\text { Type }\end{array}$ & $\begin{array}{l}\text { Type } \\
\text { (power) }\end{array}$ \\
\hline $\begin{array}{l}\text { L. Frazier [6] } \\
\text { Hugues } \\
\text { MDR-1A }\end{array}$ & 0.915 & $\begin{array}{l}2 \text { Antennas } \\
\text {-omnidir } \\
\text { - } 9 \mathrm{~dB}\end{array}$ & - & $+/-45^{\circ}$ & $\begin{array}{l}0 \mathrm{D} \\
\text { Audio } \\
\text { tone }\end{array}$ & $\begin{array}{l}\text { CW } \\
\text { RADAR } \\
(10 \mathrm{~mW})\end{array}$ \\
\hline $\begin{array}{l}\text { L. Frazier [7] } \\
\text { Hugues } \\
\text { 2D-CPR }\end{array}$ & $\begin{array}{c}0.95 \\
0.7-1.2\end{array}$ & $\begin{array}{l}2 \text { Antennas } \\
\text { - array } \\
(9 \mathrm{~dB})\end{array}$ & $15 \mathrm{~cm}$ & $+1-45^{\circ}$ & $\begin{array}{l}2 \mathrm{D} \\
\text { Screen } \\
\text { monitor }\end{array}$ & $\begin{array}{l}\text { FMCW } \\
\text { RADAR } \\
(40 \mathrm{~mW})\end{array}$ \\
\hline $\begin{array}{l}\text { E. Greneker } \\
\text { Georgia Tech } \\
\text { Radar [8-9] } \\
\text { Flashlight } \\
\end{array}$ & 10.52 & $\begin{array}{l}\text { Antenna } \\
\text { - Parabolic } \\
(40 \mathrm{~dB})\end{array}$ & - & $+/-16^{\circ}$ & $\begin{array}{l}0 \mathrm{D} \\
\text { Bar- } \\
\text { graph }\end{array}$ & $\begin{array}{l}\text { FMCW } \\
\text { RADAR } \\
(30 \mathrm{~mW})\end{array}$ \\
\hline $\begin{array}{l}\text { D. Falconer } \\
\text { SRI }[10] \\
\text { International }\end{array}$ & $0.2-0.45$ & $\begin{array}{l}3 \text { Antennas } \\
\text { - omnidir. }\end{array}$ & $\mathrm{Im}$ & Large & $\begin{array}{l}2 \mathrm{D} \\
\text { Screen } \\
\text { monitor }\end{array}$ & $\begin{array}{l}\text { FMCW } \\
\text { diff. } \\
\text { RADAR } \\
(10 \mathrm{~mW})\end{array}$ \\
\hline
\end{tabular}


obtained using a sweep-frequency and trilateration technique. The frequency sweep provides the downrange measurement and the trilateration provides the cross range coordinate. The location accuracy of the system is determined by the transmitted bandwidth and the distance between the receiver antennas. The radar output signal is displayed on a screen monitor. The nominal range in the open is approximately $25 \mathrm{~m}$. Through $15 \mathrm{~cm}$ of steel reinforced concrete this drops down to $12 \mathrm{~m}$.

\subsection{UWB radar}

UWB radar uses very narrow or short duration pulses that result in very large, or wideband, transmission bandwidths. The Federal Communication Commission (FCC) adopted a report on using this technology with imaging systems, but with certain frequency and power limitations: systems must be operated below $960 \mathrm{MHz}$ or within the frequency band $1.99-10.6 \mathrm{GHz}$.

There are less than ten laboratories throughout the world, which work on the UWB radar application "detection/vision through the walls". Company Time Domain (USA) is first producer of this system. Lawrence Livermoore National Laboratory (LINL) with radar MIR (Micropower Impulse Radar) is able to detect a man through a concrete wall of $40 \mathrm{~cm}$. The laboratory Cambridge Consultants (UK) evaluates their first prototype, PRISM 200. The Moscow Aviation Institute (Russia) realized some UWB radar prototypes that operate in different frequency (from $800 \mathrm{MHz}$ to $1,5 \mathrm{GHz}$ ). Technical specifics are mentioned at table 3.

Other companies or laboratories also work on the subject, but they separate the communication relating to the projects. Thus, information about their prototypes is

Table 3. State-of-the-art UWB technology

\begin{tabular}{|c|c|c|c|c|}
\hline $\begin{array}{c}\text { Authors, } \\
\text { Laboratory/ } \\
\text { Company }\end{array}$ & $\begin{array}{c}\text { Prototype, } \\
\text { Centre } \\
\text { Frequency } \\
(\mathrm{GHz})\end{array}$ & $\begin{array}{c}\text { Bandwidth/ } \\
\text { spatial } \\
\text { resolution }\end{array}$ & Range & $\begin{array}{c}\text { Field of view/ } \\
\text { Power }\end{array}$ \\
\hline $\begin{array}{c}\text { L. Fullerton } \\
\text { Time Domain [11] }\end{array}$ & $\begin{array}{c}\text { RadarVision } \\
3,85\end{array}$ & $\begin{array}{c}3,5 \mathrm{GHz} \\
5 \mathrm{~cm}\end{array}$ & $10 \mathrm{~m}$ & $\begin{array}{c}\text { Hor. : }+/-60^{\circ} \\
\text { Ver. : }+/-45^{\circ} \\
50 \mu \mathrm{W}\end{array}$ \\
\hline $\begin{array}{c}\text { Mc Ewan } \\
\text { LLNL [12] }\end{array}$ & $\begin{array}{c}\text { MIR } \\
2,5\end{array}$ & $\begin{array}{c}1 \mathrm{GHz} \\
15 \mathrm{~cm}\end{array}$ & $50 \mathrm{~m}$ & - \\
\hline $\begin{array}{c}\text { Cambridge } \\
\text { consultants [13] }\end{array}$ & $\begin{array}{c}\text { PRISM 200 } \\
1,7-2,2\end{array}$ & $\begin{array}{c}0,5 \mathrm{GHz} \\
30 \mathrm{~cm}\end{array}$ & $20 \mathrm{~m}$ & $\begin{array}{c}\text { Hor. : }+/-70^{\circ} \\
\text { Ver. : }+/-60^{\circ}\end{array}$ \\
\hline $\begin{array}{c}\text { I. Immoreev } \\
\text { MAI [14] }\end{array}$ & 1 & $0,8 \mathrm{GHz}$ \\
$0,5 \mathrm{~m}$ & $3 \mathrm{~m}$ & $240 \mu \mathrm{W}$ \\
\hline $\begin{array}{c}\text { J. Tatoian [15] } \\
\text { Eureka aero }\end{array}$ & ImpSAR & $3,5 \mathrm{GHz}$ & $100 \mathrm{~m}$ & - \\
\hline
\end{tabular}


unavailable. For example, there can be mentioned the company Camero (Israel) and its radar system Xaver 800, then companies Satimo (France), Akela (USA), University of Rome (Italy) and Defense R\&D Canada.

\section{UWB radar technology}

\subsection{Description of UWB radar}

Mostly, clear picture of the watching scene is not necessary, because the relevant information: number of people, positions, speed of movement, etc is sufficient. UWB radar is a very good solution for obtaining this information, because it presents a lot of advantages compared to other systems [16]:

- A good capability to penetrate wall and floor materials.

- A good picture spatial resolution (approximately ten centimeters). The wider the bandwidth radar uses, the finer the resolution it obtains.

$$
\Delta R=\frac{V}{2 n \Delta F}
$$

where $\Delta R$ is the spatial resolution, $V$ is propagation speed of impulse, $n$ is frequency step and $\Delta F$ is bandwidth.

- A possibility to identify targets due to the great numbers of emitting frequencies.

- A noise robustness due to large bandwidth.

UWB radar is based on emitting ultra short impulses from dedicated wide bandwidth. As its name indicates, UWB radar is a system allowing the transmission and then reception of a signal, which is reflected by a target. In this case, the signals are represented by impulses, which have the property to traverse walls and to be reflected back by human skin.

The radar core is based on Gaussian impulse transmitter/receiver modules which allow the evaluation of the features of UWB technology. These two modules permit variable configuration. Firstly the module can be configured as the impulse transmitter and secondly as the impulse receiver. The centre emitting frequency is $4,7 \mathrm{GHz}$ and its bandwidth is $3,2 \mathrm{GHz}$.

These modules (initially designed for communication in UWB) have reconfigured hardware (antennas) and software, in order to be able to use these as the radar UWB. Our prototype is the bistatic radar type. An omnidirectional antenna is mounted on the output of a Gaussian impulses generator (transmitter) and a directional antenna on the receiver input. Then it follows ADC (analog-to-digital converters), correlators and the directional antenna (gain $7 \mathrm{~dB}$, field of view $+/-45^{\circ}$ ) [17]. This disposition allows a spatial resolution of $5 \mathrm{~cm}$ (formula $1 ; n=1$ and $V=3 \cdot 10^{8} \mathrm{~m} / \mathrm{s}$ ) 


\subsection{Results and discussion}

First of all, the deformation and the delay of UWB impulse as it goes through the wall were studied.

UWB impulses were emitted in free space to verify if correct propagation speed in environment was obtained (figure 1). Then the deformation and the delay of UWB impulses in this scene configuration were measured: distance between transmitter and receiver was 3 metres. Just in front of the receiver a $22 \mathrm{~cm}$ thick wall was situated.

Figure 1 shows the observed propagation delay $1,5 \mathrm{~ns}$ which is caused by the wall. It is difficult to compare this experimental value with theoretical value, because the wall thickness is not homogenous; the structure of the wall is breeze block. In practice, if UWB impulse is going through the $22 \mathrm{~cm}$ thick wall then the UWB impulse is propagated through a thickness of $11 \mathrm{~cm}$ of concrete. This corresponds to a theoretical propagation delay: $\tau=\left(d \times \sqrt{\varepsilon_{r}}\right) / c=1, \operatorname{lns}$, where $d$ is the thickness of the concrete itself, $\varepsilon_{r}$ is dielectric constant of medium $\left(\varepsilon_{r}=10\right), c$ is the speed of light in free space (air). The difference between the calculated and experimental value is due to simplification of wall thickness. The deformation of impulse which was propagated through the wall (see figure 1 ) is caused partially by the dispersion during propagation inside the wall but also by the imperfect impedance adaptation of antenna situated just near the wall.

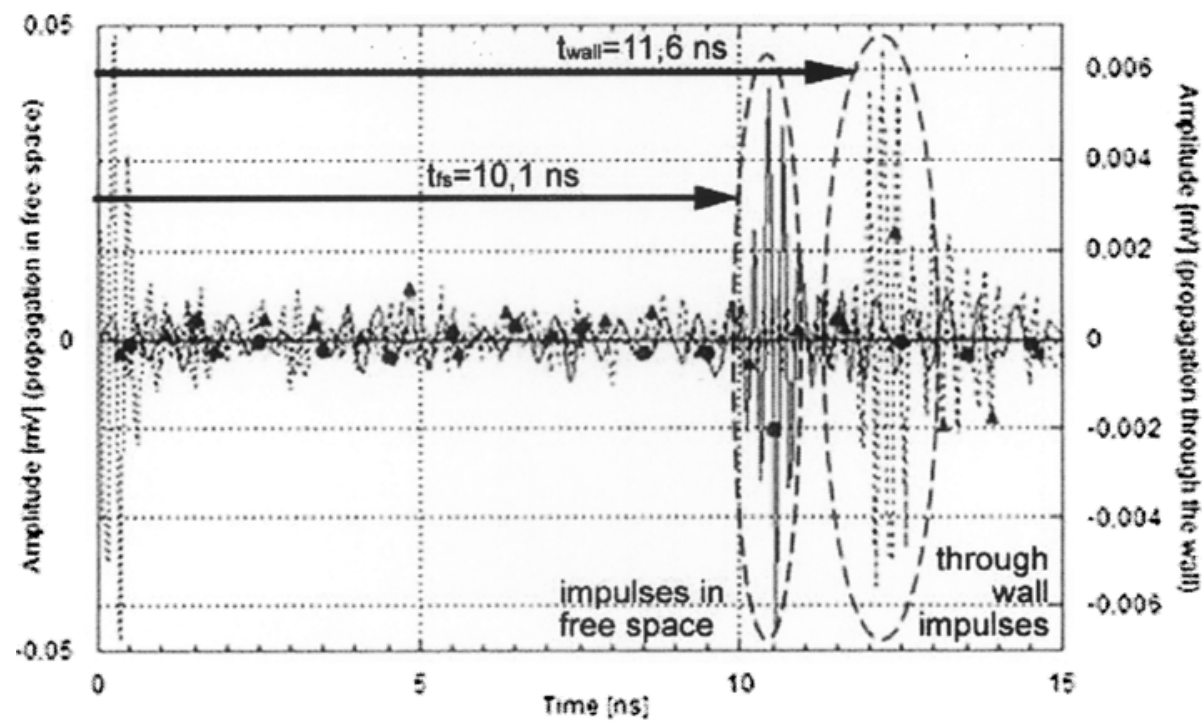

Fig. 1 : Influence of the $22 \mathrm{~cm}$ thick wall on the UWB impulse propagation. $\mathrm{t}_{\mathrm{fs}}$ corresponds to impulse propagation time in free space, $t_{\text {wall }}$ corresponds to impulse propagation time going through the wall. The difference between propagation time $\mathfrak{t}_{\mathrm{fs}}$ and $\mathfrak{t}_{\text {wall }}$ is equal $1,5 \mathrm{~ns}$, which indicates propagation delay caused by the wall. 
Secondly, an experiment was carried out for the validation of our UWB radar with an observation scene through a $15 \mathrm{~cm}$ thick concrete wall. The scene configuration, the parameters of the measured scene such as the presence (or not) of a human body and the open (or closed) door, are represented in figure 2 . Our disposition actually permits observation of the scene in one direction only. The field of view is associated with an antenna pattern.

Figures 3 to 6 present the different echoes observed through the wall. The scene configuration is described in figure 2. In figure 3 and 4 respectively the observed scene is shown with an open and closed door. In figure 5 and 6 respectively the observed scene is shown with the absence of a human body and presence of a human body in the corridor.

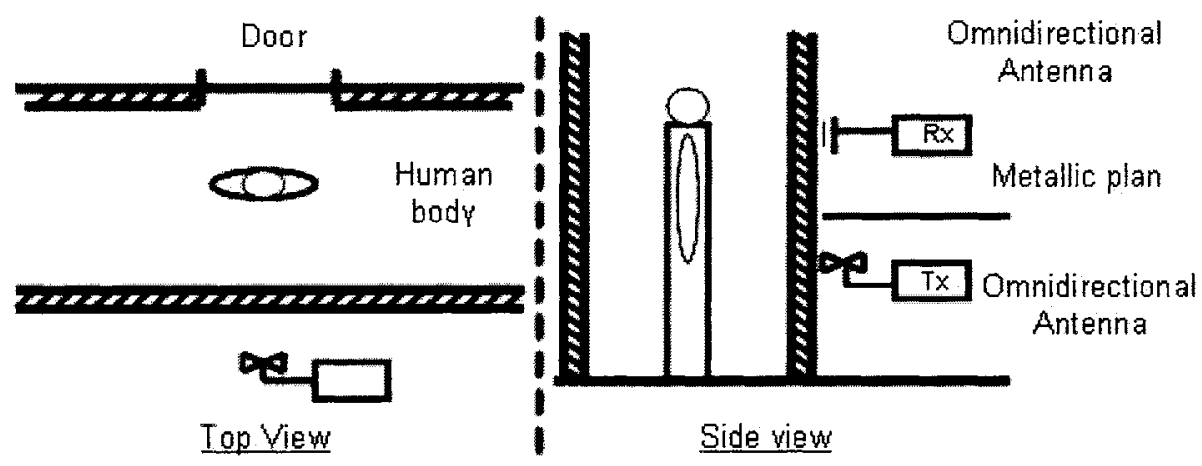

Fig. 2. Measured scene. The thickness of the concrete wall is $15 \mathrm{~cm}$.

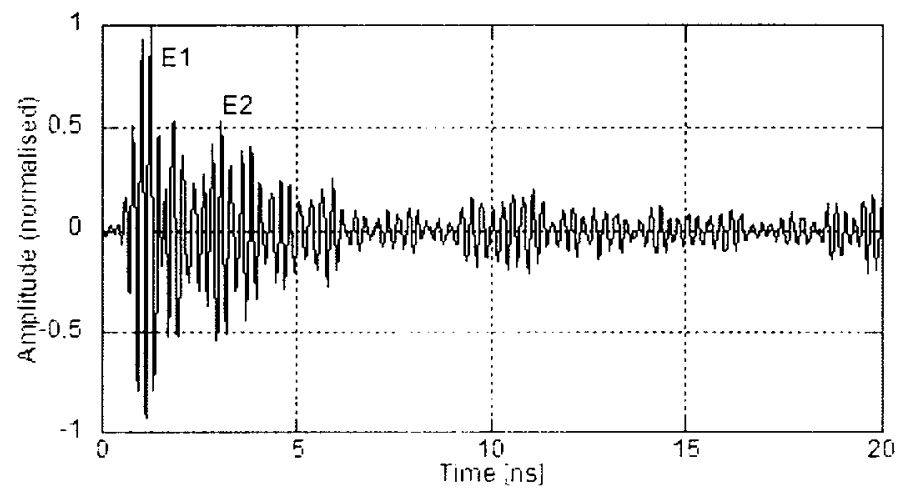

Fig. 3. Radar echoes received through a $15 \mathrm{~cm}$ thick concrete wall. Measured scene with open door. The echo "E1" corresponds to the direct field received by the receiver, the echo "E2" is due to the reflection on the wall. 
Pulses marked "El" correspond to the direct field received by the receiver, the echoes "E2" are due to the reflection on the wall. The presence of the echo "E3" in figure 6, and its absence in figure 5, highlights the detection of the human body located in the corridor. The echoes "E4" correspond to a wave reflected by the door when it is closed. These signals show the possibilities to recover complementary information, other than the presence or absence of a human body located behind a wall.

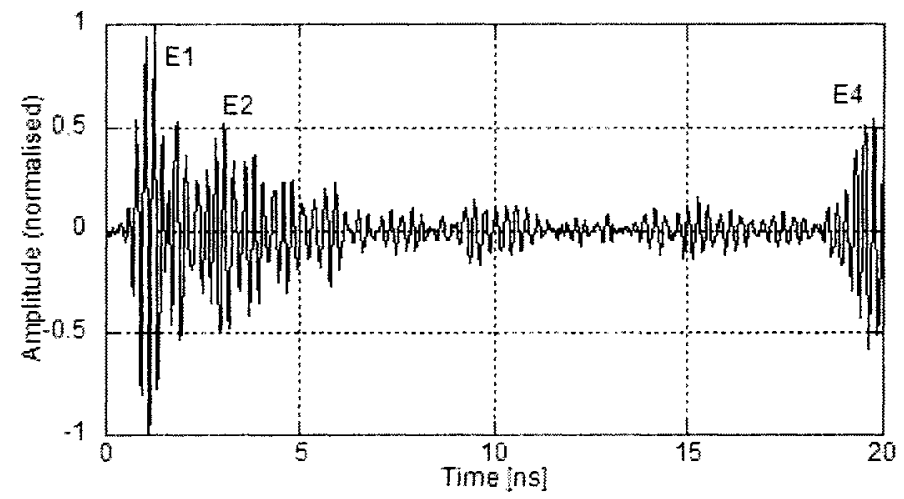

Fig. 4. Radar echoes received through a $15 \mathrm{~cm}$ thick concrete wall. Measured scene with closed door. The echo "E1" is due to direct field received by the receiver, the echo "E2" is due to the reflection on the wall. The echo "E4" is due to a wave reflected by the closed door.

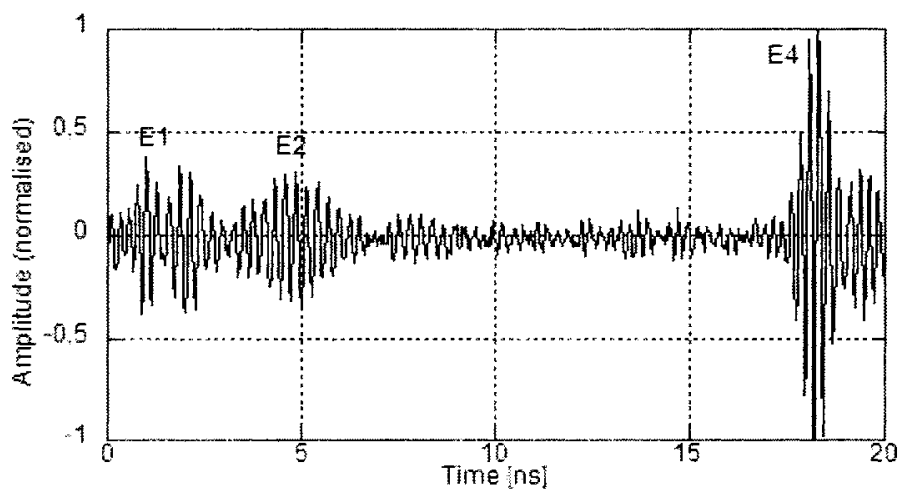

Fig. 5. Radar echoes received through a $15 \mathrm{~cm}$ thick concrete wall. Measured scene with absence of a human body. The echo "El" corresponds to direct field received by the receiver, the echo " $\mathrm{E} 2$ " is due to the reflection on the wall. The echo " $\mathrm{E} 4$ " is due to a wave reflected by the closed door. 


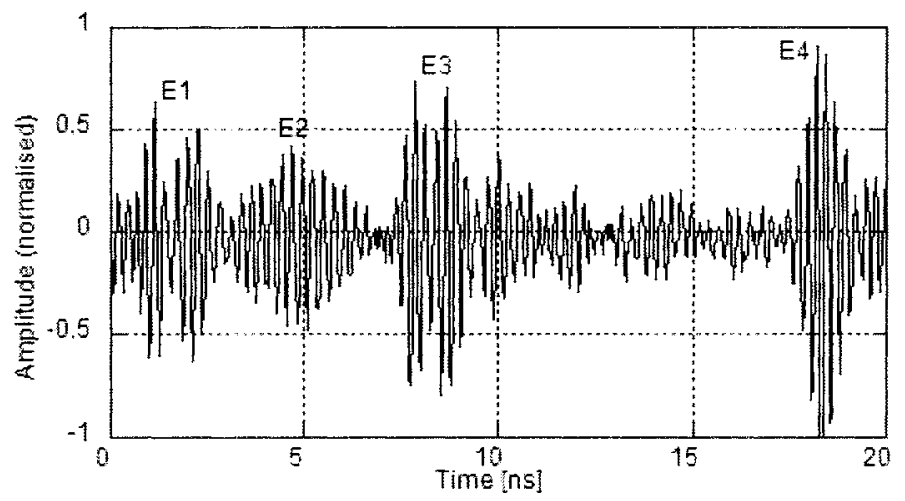

Fig. 6. Radar echoes received through a $15 \mathrm{~cm}$ thick concrete wall. Measured scene with presence of a human body. The echo "E1" corresponds to direct field received by the receiver, the echo "E2" is due to the reflection on the wall. The echo "E3" corresponds to presence of the human body. The echo "E4" is due to a wave reflected by the closed door.

\section{Conclusion and future implication}

The currently developed UWB radar system can detect a human body located behind a wall and some parameters of the scene. But this system is limited by scene observation in one direction. We are developing a mechanic sweep system to permit the acquisition of a scene in $2 \mathrm{D}$ (typically a space of $10 \times 10 \mathrm{~m}^{2}$ ). This radar will be able to give us the number of people in a space and their positions.

Acknowledgements. This research work was supported by Czech Technical University's grant No. CTU0715013. Authors would like to thank Ms J. Coates for help with English expression.

\section{References}

1. N. Currie, D. Ferris, R. McMillan and M. Wicks, "New law enforcement applications of millimeter wave radar", Proceedings of SPIE, Vol. 3066, pp. 10-23, (1997).

2. G. Huguenin, "millimeter-wave video rate imagers", Proceedings of SPIE, Vol. 3064, pp. 34-45, (1997).

3. J. Svedin and L-G. Huss, "A new staring $94 \mathrm{GHz}$ focal plane array", Proceedings of SPIE, Vol. 5619, pp. (2005).

4. R. Olsen, J. Lovberg, R. Chou, C. Martin and J. Galliano, "Passive millimeter-wave imaging using a sparse phased-array antenna", Proceedings of SPIE, Vol. 3064, pp. 63-70, (1997).

5. B. Blume, J. Wood and F. Downs, "Naval special warfare PMMW data collection results", Proceedings of SPIE. Vol. 3378, pp. 86-94, (1998). 
6. L. Frazier, "Surveillance through walls and other opaque materials", IEEE AES Systems Magazine, pp. 6-9, (Oct 1996).

7. D. Ferris and N. Currie, "A survey of current technologies for through-the-wall surveillance (TWS)", Proceedings of SPIE, Vol. 3577, pp. 62-72, (1998).

8. E. Greneker, "Radar flashlight for through-the-wall detection of humans", Proceedings SPIE 3375 pp. 280-285 (1998).

9. E. Greneker, J. Geisheimer, D. Adreasen, O. Asbel, B. Stevens. B. Mitchell "Development of inexpensive RADAR Flashlight for Law enforcement and corrections applications", Final Technical report on contract NIJ 98-DT-CX-K003, (Apr 2000).

10. Falconer, K. Steadman and D. Watters, "Through-the-wall differential Radar", Proceedings of SPIE, Vol. 2938, pp. 147-151, (1997).

11. K. Siwiak Time Domain Corp. "An introduction to Ultra-Wideband wireless technology", IEEE VTC (Vehicular Technology Conference), May 2001.

12. F. Nekoogar, F. Dowla, A. Spiridon "Rapid synchronisation of Ultra wide band transmitted reference receivers" Wireless, July 2004. Calgary Canada.

13. Gordon Oswald Cambridge consultants "UWB radar Applications" Ultra-WideBand conference, 1999. Downtown Washington DC.

14. Igor Y. Immoreev, P.G. Sergey, V. Samkov, The-Ho Tao "Short - distance Ultra-Wideband Radars. Theory and designing", Radar 2004. International Conference on Radar Systems, october 2004, pp. $211-213$. Toulouse. France.

15. http://eurekaaerospace.com/impsar.php

16. Ultra-Wideband Radar Technology, J. D. Taylor, 2001, CRC Press.

17. A.C. Lepage, X. Begaud, G. Le Ray and A. Sharaiha «F-probe fed Broadband Triangular Patch Antennas Mounted on a Finite Ground Plane », IEEE Antennas and Propagation Symposium, Monterey, USA, June 2004. 